\title{
Laser in Proctology: A New Hope in Treating the Distressing Anal Diseases
}

\author{
ASMT Rahman
}

Benign anorectal conditions i.e. hemorrhoids, anal fissure, anorectal fistulae of different varieties pose a great problem to a number of people in our country. Some western reports show that at least once in their lives, more than $80 \%$ of the world's population suffer from benign anorectal conditions ${ }^{1}$. All these conditions are as old as the history of human civilization. The oldest convincing descriptions of hemorrhoids and other diseases of the anus and anal canal date back to $1500 \mathrm{BC}$ in Mesopotamia. But there are even older records in Indian and Chinese literature, although we do not know exactly how old these are. The Egyptian "Chester Beatty Medical Papyrus" from about 1200 BC deals exclusively with these diseases and the old Europeans as the Greek Hippocrates (460 to $370 \mathrm{BC}$ ) and Galen (129 to 216 AD), who worked in Rome, wrote numerous extensive papers on the same subject. More recently, there is at least one new article every week published in medical periodicals on this topic ${ }^{2}$.

Surgeons around the world are still struggling to provide the best surgical treatment of these anorectal conditions. All these diseases are blamed for its recurrence even when the surgery is done in highly specialized centers. Some procedures increase the morbidity especially when aggressive surgical procedures are attempted, i.e. incontinence after fistula surgery, large perianal wound in sinus tract excision. Role of many non-surgical methods in treating benign anorectal diseases to reduce the morbidity is well established. Injection sclerotherapy and banding in hemorrhoids, seton in fistula etc. are still in use.

During the last few decades world's surgery has moved to conservative approach with aim to provide total patient care avoiding unnecessary extensive excision of course based on solid evidence i.e. breast conservation in breast cancer, lobectomy for small thyroid cancer, organ salvage by increasing use of neoadjuvant therapy etc.

In treating benign anorectal diseases we have seen many newer surgical techniques in the last couple of decades. They are essentially minimally invasive, with less morbidity. Outcome is comparable to the existing or gold standard procedures as evident in published literatures from every corners of the world. In 1998 Dr. Antonio Longo, an Italian surgeon published his landmark article on stapled hemorrhoidopexy ${ }^{3}$. After that the procedure was widely adopted by European surgeons and now it is practiced worldwide. Sir Arun Rojanasakul from Thailand developed a new technique of perianal fistula surgery named as LIFT (Ligation of inter-sphincteric fistula tract) in $2005^{4}$. The first report of preliminary healing result from the procedure was $94 \%$ in $2007^{5}$. Both the procedures are less traumatic, left minimal perianal wound with faster recovery than conventional techniques.

In spite of many modifications made to the hemorrhoidal surgical techniques, postoperative pain

1. Dr. ASM Tanjilur Rahman, MBBS, FCPS (Surgery), Junior Consultant, Dept of Surgery, Faridpur Medical College Hospital, Faridpur.

Address of correspondence :

Dr. ASM Tanjilur Rahman, MBBS, FCPS( Surgery), Junior Consultant, Dept of Surgery, Faridpur Medical College Hospital, Faridpur. Phone: +88-01711965277, E-mail: tanji117@hotmail.com and discomfort remain the major concerns. For this reason, mildly symptomatic patients often refuse to undergo surgical treatment for this benign disease. In addition, it is not justified to treat low-grade hemorrhoidal patients using the same surgical techniques.

Laser ablation has opened new possibilities for the minimally invasive treatment of hemorrhoids. Carbon dioxide, argon, and Nd:YAG lasers are the most commonly used lasers for laser hemorrhoidectomy. Recently the diode laser system has been introduced which is more precise and comfortable to work with. The laser beam causes tissue shrinkage and degeneration at different depths depending on the laser power (irradiance) and the duration of laser light application. Recent evidence has supported this modality treatment for symptomatic hemorrhoids. It is reported that the application of laser technique in the treatment of hemorrhoids was safe, effective, and painless $^{6}$.

Fistula laser closure (FiLaC) and DLPL (Distal Laser and Proximal Ligation) are novel sphincter-saving procedures for the treatment of anal fistula. Primary closure of the track is achieved using laser energy emitted by a radial fiber connected to a diode laser. The energy causes shrinkage of the tissue around the radial fiber with the aim of closure of the track.

So ample evidences are being generated throughout the world in use of laser in treating benign anorectal disorders resulting minimal pain, shorter duration of surgery and hospital stay, early return to work, devoid of large perianal wound, does not require dressing weeks together and hence cost effective. We the surgeons of our country should look forward to adopt this effective newer technology in minimally invasive surgery in proctology to reduce the sufferings of the patients with distressing anorectal conditions.

\section{References :}

1. Helio P, Raduan H, Janaina D, Nilza L, Igor M, Cla'udio C. A New Method For Hemorrhoid Surgery: Intrahemorrhoidal Diode Laser, Does It Work? Photomedicine and Laser Surgery 2009; 27:819-23.

2. Claus F. Everything you ever wanted to know about the history of haemorrhoids [Internet]. [Odense University Hospital, Denmark]: Claus Fenger, Professor emeritus (pathology); 2018. Available from: https://sciencenordic.com/denmark-forskerzonen-mens health/everything-you-ever-wanted-to-know-about-the-history-of haemorrhoids/1461058Sciencenordic

3. Longo A. Treatment of haemorrhoidal disease by reduction of mucosa and haemorrhoidal prolapse with a circular stapling device: a new procedure. 6th World Congress of Endoscopic Surgery. Mundozzi Editore: Naples, 1998;777-84.

4. Rojanasakul A. LIFT procedure: a simplified technique for fistulain-ano. Tech Coloproctol. 2009; 13(3):237-40.

5. Rojanasakul A, Pattanaarun J ,Sahakitrungruang C, Tantiphlachiva $\mathrm{K}$. Total anal sphincter saving technique for fistula-in ano; the ligation of intersphincteric fistula tract. J Med Assoc Thai. 2007; 90(3):581-6.

6. Naderan M, Shoar S, Nazari M, Elsayed A, Mahmoodzadeh H, Khorgami Z. Randomized Controlled Trial Comparing Laser IntraHemorrhoidal Coagulation and Milligan-Morgan Hemorrhoidectomy. Journal of investigative surgery 2017; 30(5):325-31. 